University for Business and Technology in Kosovo

UBT Knowledge Center

UBT International Conference

2017 UBT International Conference

Oct 27th, 4:15 PM - 6:00 PM

\title{
Review of artificial intelligence development, its impact and its challenges
}

Litvane Spahija

University of Tetova, litvana.spahija@gmail.com

Festim Halili

University of Tetova, festim.halili@unite.edu.mk

Follow this and additional works at: https://knowledgecenter.ubt-uni.net/conference

Part of the Computer Engineering Commons, and the Computer Sciences Commons

\section{Recommended Citation}

Spahija, Litvane and Halili, Festim, "Review of artificial intelligence development, its impact and its challenges" (2017). UBT International Conference. 87.

https://knowledgecenter.ubt-uni.net/conference/2017/all-events/87

This Event is brought to you for free and open access by the Publication and Journals at UBT Knowledge Center. It has been accepted for inclusion in UBT International Conference by an authorized administrator of UBT Knowledge Center. For more information, please contact knowledge.center@ubt-uni.net. 


\title{
Review of artificial intelligence development, its impact and its challenges
}

\author{
Litvane Spahija $^{1}$, Festim Halili ${ }^{1}$ \\ ${ }^{1}$ Faculty of Mathematics and Natural Sciences, Department of Informatics, \\ University of Tetovo, Macedonia \\ litvana.spahija@gmail.com, festim.halili@unite.edu.mk
}

\begin{abstract}
The field of Artificial Intelligence, which started roughly half a century ago, has a turbulent history. In the 1980s there has been a major paradigm shift towards embodiment. While embodied artificial intelligence is still highly diverse, changing, and far from "theoretically stable", a certain consensus about the important issues and methods has been achieved or is rapidly emerging. With the popularization of the Internet, permeation of sensor networks, emergence of big data, increase in size of the information community, and interlinking and fusion of data and information throughout human society, physical space, and cyberspace, the information environment related to the current development of artificial intelligence (AI) has profoundly changed. AI faces important adjustments, and scientific foundations are confronted with new breakthroughs, as AI enters a new stage: AI 2.0.

The goals of this research article are to review and synthesize the literature about service quality delivery through Artificial intelligence, describe what is known about the topic, and develop an agenda for needed research.
\end{abstract}

Keywords:Artificial Intelligence 2.0, Big Data, Human-machine, hybrid-augmented intelligence, Autonomous-intelligent system, Industry.

\section{Introduction}

The purpose of this paper is to analyze Artificial Intelligence from various online literatures to extract a result that confirms the importance of a successful business venture based on the use. As a result of this research i have had the increasing presence of various online companies and the delivery of various services such as transactions, sales or other services where all these are unimaginable to function without a complex web service functionality.

Over the last 50 years Artificial Intelligence (AI) has changed dramatically from a computational discipline into a highly trans disciplinary one that incorporates many different areas. Embodied AI, because of its very nature of being about embodied systems in the real physical and social world, must deal with many issues that are entirely alien to a computational perspective: physical organisms in the real world, whether biological or artificial, are highly complex and their investigation requires the cooperation of many different areas. In recent years, industry, the media, and political organizations have shown strong interest in artificial intelligence (AI), with AI-related research and applications rapidly increasing at home and abroad. Industry is interested in potential uses of AI. According to a report (Varadharajan, 2016), issued by the venture capital corporation CB Insights in the US in July 2016, Google, Microsoft, Twitter, Intel, Apple, and other information technology giants have acquired about 140 entrepreneurial firms in the field of AI since 2011. During the first six months of 2016, 
investment in AI exceeded that realized throughout 2015, and 200 AI-related companies have raised 1.5 billion dollars in the stock market.

A large number of mergers and acquisitions, along with the influx of capital, are accelerating the integration of AI technology with applications, thereby increasing the already rapid transformation of the related economy. For example, Google caused uproar when it offered to purchase the neural network company DNN research, which was comprised of a few members and founded by Professor Geoffrey Hinton from the University of Toronto, at a high price in 2013. The deep-learning method is currently the hottest technology in industrial circles and has helped Google improve the accuracy of picture searches. This technology has also become a core technology associated with Google Glass, unmanned ground vehicles, and other projects. Google boasts about itself that it is developing from "mobile first" toward "AI first."

The integration of AI with industrial demands has forced significant changes in modes of service. For example, the chatting robot Xiaobing that was developed by Microsoft is guiding a transformation from a traditional graphical interface to an interactive interface with naturallanguage and emotional understanding. In June 2016, Microsoft acquired the social-networking site LinkedIn and prepared to reconstruct the Internet community using AI technology. In addition, the Watson system: (Ferrucci,2013) developed by IBM has been operationally utilized in hospitals to rapidly screen millions of patient records for histories of cancer treatment in order to provide suggestions for diagnosing leukemia and providing therapeutic schedules; thereby changing the paradigm of oncotherapy and clinical diagnosis. Furthermore, Baidu was designated as the "smartest corporation" due to its development of machine translation, natural-language understanding, and smart vehicles: ( Pan., 2016).

\section{Materials and methodology}

Descriptive and analytical methodology has been used for the analysis of the Artificial Intelligence (AI). For the process of analysis, a lot of secondary sources such as a different articles in journals and different articles have been discussed.

In this research article the authors have analyzed various works published in journals and scientific conferences related to the topic of Artificial Intelligence (AI) and tried to answer in these questions based in the related article from different journals:

i) To know if the large number of mergers and acquisitions, along with the influx of capital, are accelerating the integration of AI technology with applications, thereby increasing the already rapid transformation of the related economy

ii) To know what could the increases in economic output generated by AI mean for corporate profitability spanning multiple industries?

iii) To knowthe impact of AI on profits by industry Share-of-profit increase per industry between baseline in 2035 and AI steady state in 2035. (\%).

When the field started initially, roughly half a century ago, intelligence was essentially viewed as a computational process. Research topics included abstract problem solving and reasoning, knowledge representation, theorem proving, formal games like chess, search techniques, and written - natural language, topics normal associated with higher level intelligence. It should be mentioned however, that in the 60 s there was a considerable amount of research on robotics in artificial intelligence at MIT, SRI, and CMU. But later on the artificial intelligence research community has not paid much attention to this line of work. Successes of the classical approach by the mid 1980s, the classical, computational or cognitivistice approach, had grown into a large discipline with many facets and has brought forward many successes in terms of computer and engineering applications. If you start your favorite search engine on the Internet, you are, among many others, employing clever machine learning algorithms. Text processing system utilizes matching algorithms, or algorithms that try to infer user's intentions from the context of 
what have been done earlier. Controls for appliances using fuzzy logic, embedded systems (as they are employed in fuel injection systems, breaking systems, air conditioners, etc.), control systems for elevators, and trains, natural language interfaces to directory information systems, translation support software, etc., are also among the successes of the classical approach. More recently, data mining systems have been developed that heavily rely on machine learning techniques, and chess programs have been realized that beat 99.99 percent in all cases, a considerable achievement indeed!

The development of these kinds of systems, although they have their origin in artificial intelligence, has now become indistinguishable from applied informatics in general: (Pfeifer.,2004)

\section{Result}

The researchers Mark Purdy and Paul Daugherty have analyzed that that reflects annual growth rates in 2035 of gross value added (a close approximation of GDP), comparing baseline growth in 2035 to an artificial intelligence scenario where AI has been absorbed into the economy, modeled the economic impact of artificial intelligence (AI) in 16 industries: Agriculture, Forestry and Fishing Accommodation and Food Services Arts, Entertainment and Recreation Construction Education Financial Services Healthcare Information and Communication, Manufacturing Other Services Public Services Professional Services Social Services Transportation and Storage Utilities Wholesale and Retail

Table.1. Comparing baseline growth in 2035 to an artificial intelligence scenario where AI has been absorbed into the economy.[12]

\begin{tabular}{|c|c|c|}
\hline Industry & Baseline & $\begin{array}{l}\text { AI Steady } \\
\text { State }\end{array}$ \\
\hline Information $\quad \&$ & & \\
\hline Communication & 3.4 & 4.8 \\
\hline Manufacturing & 2.1 & 4.4 \\
\hline Financial Service & 2.4 & 4.2 \\
\hline Wholesale \& Recall & 2 & 4 \\
\hline $\begin{array}{l}\text { Transportation \& } \\
\text { Storage }\end{array}$ & 2.1 & 4 \\
\hline Professional Service & 2.3 & 3.8 \\
\hline Healthcare & 2.2 & 2.4 \\
\hline Construction & 2.3 & 2.4 \\
\hline
\end{tabular}




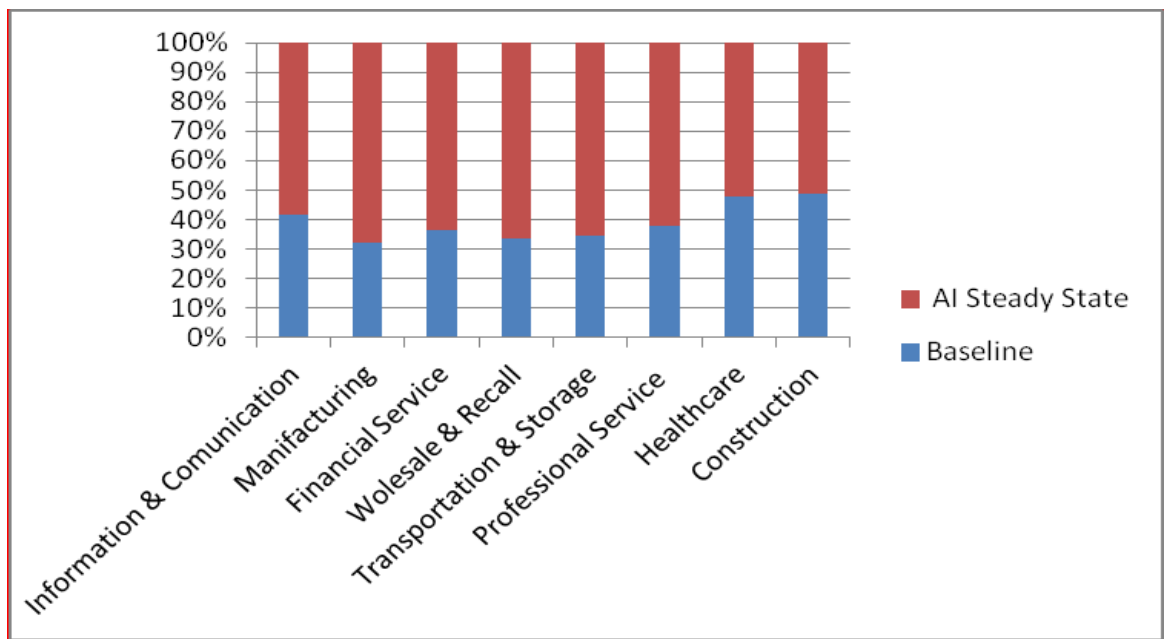

Figure 1. Annual growth rates of gross value added (a close approximation of GDP), comparing baseline growth in 2035 to an artificial intelligence scenario where AI has been absorbed into the economy. [12]

Table 2. Comparing baseline growth in 2035 to an artificial intelligence scenario where AI has been absorbed into the economy.[12]

Industry Baseline AI Steady State

\begin{tabular}{lll}
\hline $\begin{array}{l}\text { Agriculture, Forestry and } \\
\text { Fishing }\end{array}$ & 1.3 & 3.4 \\
$\begin{array}{l}\text { Accommodation and } \\
\text { Food Services }\end{array}$ & 1.4 & 3.2 \\
Utilities & 1.4 & 3.1 \\
$\begin{array}{l}\text { Arts, Entertainment and } \\
\text { Recreation }\end{array}$ & 1.9 & 3.1 \\
Social Services & 1.6 & 2.8 \\
Public Services & 0.9 & 2.3 \\
Other services & 0.7 & 1.7 \\
Education & 0.9 & 1.6 \\
\hline
\end{tabular}




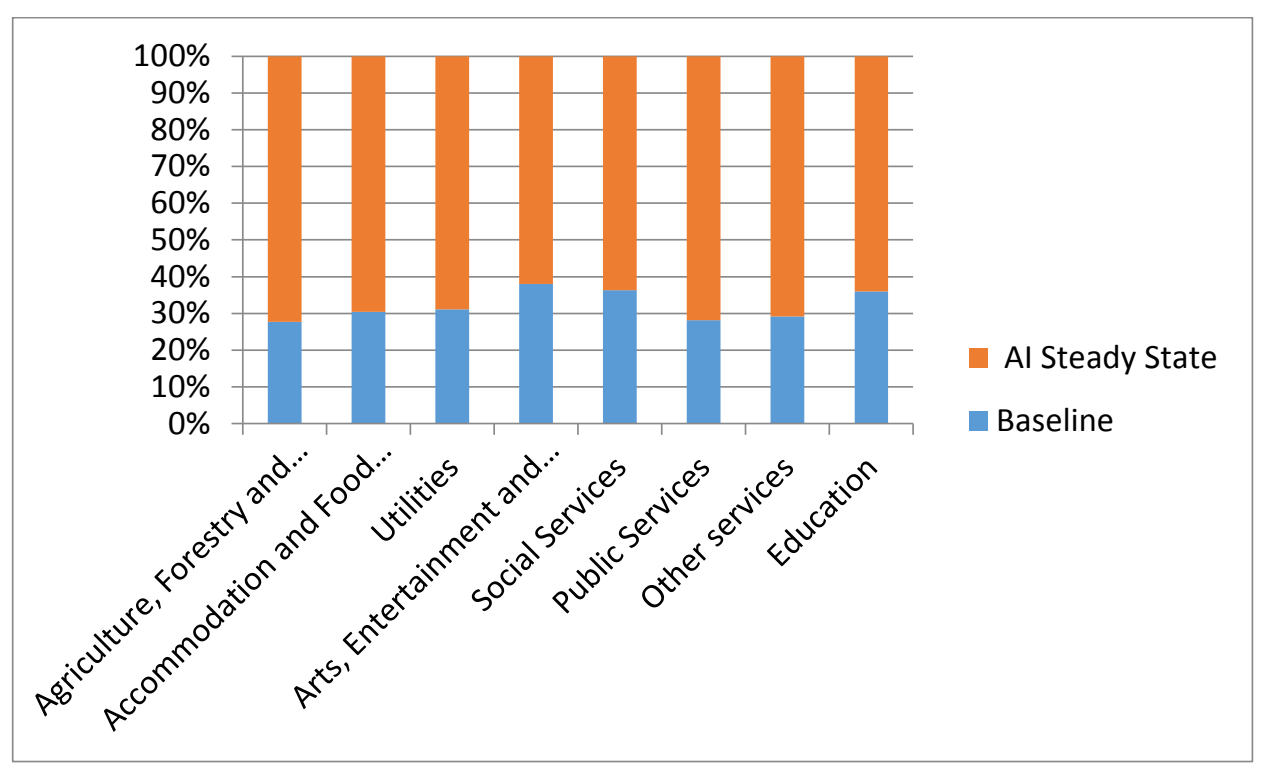

Figure 2. Annual growth rates of gross value added (a close approximation of GDP), comparing baseline growth in 2035 to an artificial intelligence scenario where AI has been absorbed into the economy. [12]

Through these channels, AI offers unprecedented profitability opportunities. Case in point: With labor-intensive sectors, such as Wholesale and Retail, Arts, Entertainment and Recreation, and Healthcare, AI augments the human workforce, enabling people to become more productive over time and redirecting their focus on critical tasks. For the Wholesale and Retail sector, this can lead to a profit increase of almost 60 percent-from US\$17 to US\$27 for every US\$100 of revenue (Figure 2). For traditionally capital-intensive industries, the AI impact on profitability can be equally dramatic. In Manufacturing, for example, faulty machines and idle equipment will become a thing of the past as AI-powered systems deliver constantly rising rates of return due to their ability to learn, adapt and evolve over time. Things like rapid prototyping or dynamic resource allocation can significantly reduce time-to-market and cut costs in the process . The net result for the sector? A share of profit increase of 39 percent.

AI has the potential to markedly increase industry growth information and Communication, Manufacturing and Financial Services are the three sectors that will benefit most from the aplication of AI. Nnual.

Annual growth rates in 2035 of gross value added (a close approximation of GDP),comparing baseline growth in 2035 to an artificial intelligence scenario where AI has been absorbed into the economy. Source Accenture and Frontier Economics[12] 


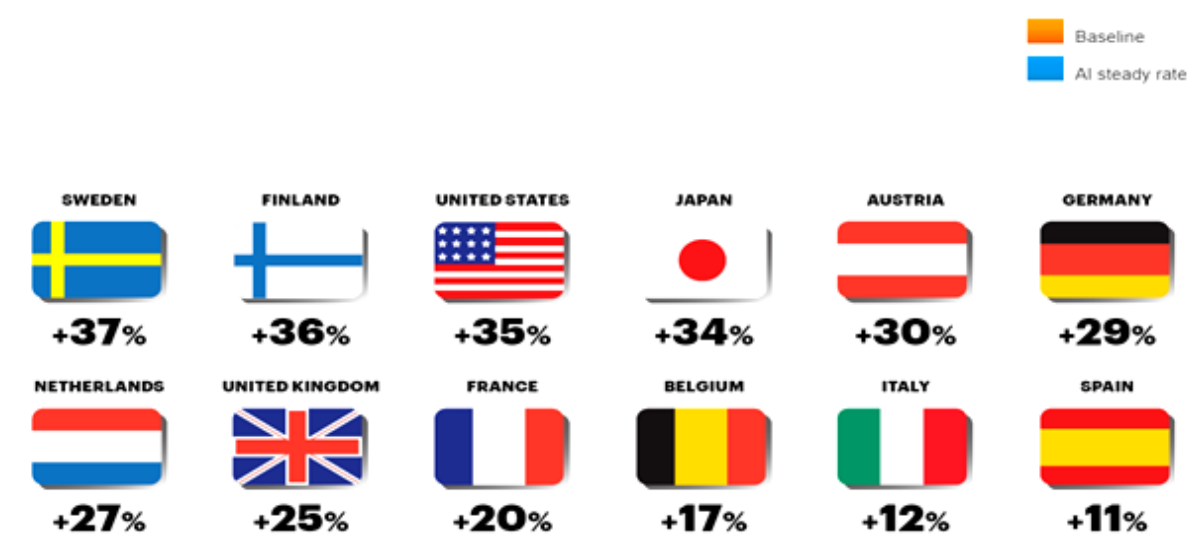

Figure 3. Percentage increase in labor productivity with AI, compared to expected baseline productivity levels in 2035.[12]

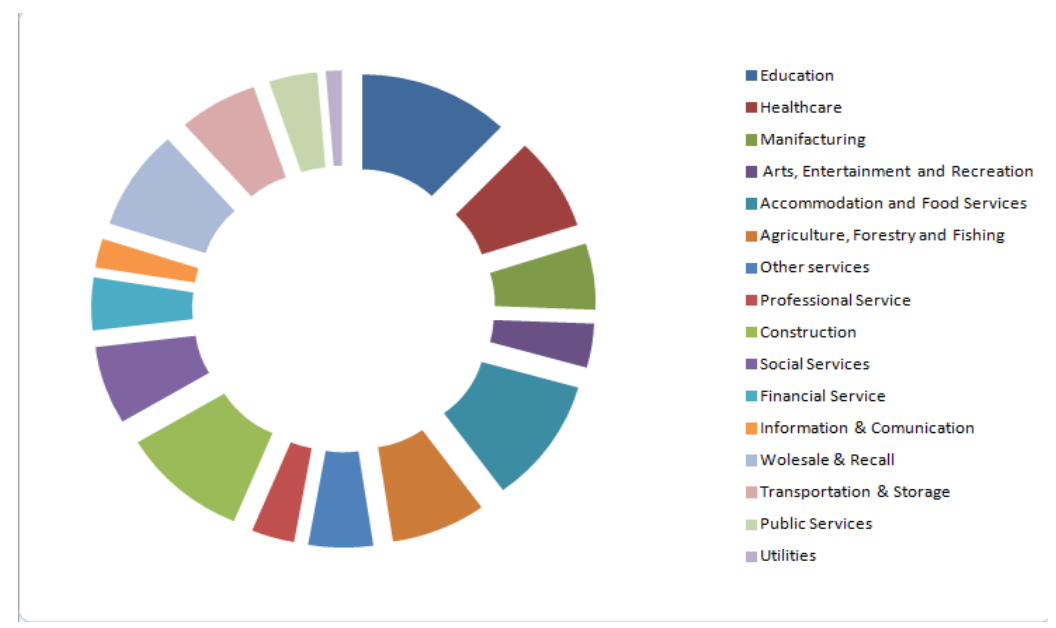

Figure 4. The impact of AI on profits by industry Share-of-profit increase per industry between baseline in 2035 and AI steady state in $2035(\%)$.[12]

\section{Conclusion}

Second, success in AI depends on advances in all of computer science. Finally, all parts of AI belong together. Success in AI requires advances in all of its disparate parts including chess, cognitive science, logic, and connectionism. Each of these experiments yields new insights that are crucial to the ultimate success of the whole enterprise. 
Significant improvements to the finish line, according to our research, AI have the potential to increase benefit rates from an average of 38 percent by 2035 in 16 industries. Accenture has identified three channels through which

AI can change the low benefit cycle at all industries: intelligent automation, work and capital augmentation, and the spread of innovation.

Future work will be invested in implementing an improved approach that solves many of the algorithm implementation challenges in order to incorporate even more artificial intelligence into the futures machines in the everyday uses of every field of life, the various industries that directly will give positive impacts to future profits.

It should also be taken into account the possibilities of the negative impacts of such a large development of artificial intelligence which we propose to be a study topic for the fast future.

\section{References}

1. Pfeifer, R., Iida, F.(2004): Embodied Artificial Intelligence: Trends and Challenges In: International Seminar Dagstuhl Castle,Germany,Springer:1-3

2. Reddy, R.(1988):Foundations and Grand Challenges of Artificial Intelligence, In: AI Magazine Volume 9 Number 4 (@) AAAI):1-12

3. Pan, Y. (2016): Heading toward Artificial Intelligence 2.0, In: Elsevier, Volume 2, Issue 4: 409-413

4. Varadharajan, D. (2016): Insights The race for AI: Google,Twitter, Intel, Apple in a rush to grab artificial intelligence startups [Internet] CB Insights, New York [cited 2016 Dec 10]. Available from:

5. https://www.cbinsights.com/blog/top-acquirers-ai-startups-ma-timeline/

6. Ferrucci, D., Levas, A., Bagchi, S.,Gondek, D., Mueller, ET. (2013): Watson beyond jeopardy! In: Elsevier, Artif Intell; 199-200: 93-105

7. Crevier, D. AI, (1993): The tumultuous history of the search for artificial intelligence, Basic, Books, Inc, New York: 7-88

8. Lighthill, J. (1973): Artificial intelligence. In: Symposium, Science Research Council, London: 3-8

9. Poli, R., Healy, M., Kameas, A. (Eds.), (2010): Theory and applications of ontology: computer applications, Springer, Berlin: 2-3

10. Auer, S., Bizer, C., Kobilarov, G., Lehmann, J., Cyganiak, R., Lves, Z., (2016): DBpedia: A nucleus for a web of open data.12-13

11. Aberer, K., Choi, K.S., Noy, N., Allemang, D., Lee, K., Nixon, L. (2007): et al. (Eds.), The semantic web, Springer, Berlin , pp. 722-735Bollacker, K., Evans, C.,

12. Paritosh, P., Sturge, T., Taylor, J., Freebase, (2008).: a collaboratively created graph database for structuring human knowledge. In: Proceedings of the 2008 ACM SIGMOD International Conference on Management of Data; 2008 Jun 9-12; Vancouver, Canada. p. 1247-1250. The world fact book [Internet]. Washington, DC,(2016): Central Intelligence Agency. [Cited 2016 Nov 20].

13. Available from: https://www.cia.gov/library/publications/the-world-factbook/

14. Mark Purdy and Paul Daugherty, (2017): How AI will reverse falling profit growth:Available from:

15. https://www.accenture.com/us-en/insight-ai-industry-growth 